\title{
Conglomerados de violência em Pernambuco, Brasil
}

\author{
Maria Luiza C. de Lima, ${ }^{1,2}$ Ricardo A. de A. Ximenes, ${ }^{1,3}$ \\ Carlos Luna Feitosa, ${ }^{2}$ Edinilsa Ramos de Souza, ${ }^{4}$ \\ Maria de Fátima P. Militão de Albuquerque, ${ }^{2}$ Maria Dilma de \\ Alencar Barros, ${ }^{5}$ Wayner Vieira de Souza ${ }^{2}$ e Tiago Maria Lapa ${ }^{2}$
}

Como citar Lima MLC, Ximenes RAA, Feitosa CL, Souza ER, Albuquerque MFPM, Barros MDA, et al. Conglomerados de violência em Pernambuco, Brasil. Rev Panam Salud Publica. 2005;18(2):122-8.

RESUMO Objetivo. Analisar o padrão espacial das taxas de mortalidade por homicídio em homens com idade de 15 a 49 anos no Estado de Pernambuco, Brasil, nos períodos de 1980 a 1984 e de 1995 a 1998, e identificar conglomerados de violência.

Métodos. Os dados sobre mortalidade foram obtidos junto ao Sistema de Informações sobre Mortalidade do Ministério da Saúde. A média das taxas de mortalidade por homicídio foi estimada por município para os dois períodos. O coeficiente de Moran, que varia de $-1 a+1$, foi calculado para explorar a dependência espacial. Um coeficiente positivo indica um conglomerado de valores semelhantes, enquanto que um coeficiente negativo indica a adjacência de valores dessemelhantes. Para localizar os conglomerados de municípios com taxas de homicídio altas e baixas, foi utilizado o indicador local de autocorrelação espacial (LISA). Por último, foi construído o mapa de Moran, que permite identificar os municípios com LISA estatisticamente significativo e, ao mesmo tempo, pode revelar se o agrupamento de municípios tem taxas de homicídio altas ou baixas.

Resultados. Os resultados do coeficiente de Moran para os períodos investigados apresentaram valores positivos $(0,392$ e 0,291 , respectivamente $)$ e altamente significativos $(\mathrm{P}<0,001)$. Comparando-se os dois períodos analisados através do mapa de Moran, foi possivel observar, no primeiro período, um conglomerado de altas taxas de homicídios predominante na Região da Mata Sul, próxima à Região Metropolitana. No segundo, foram identificados dois conglomerados, um predominantemente urbano, situado na Região Metropolitana, e outro no interior do Estado, no chamado Polígono da Maconha.

Conclusões. O estudo sugere que não são exatamente as condições socioeconômicas as responsáveis pelos conglomerados de homicídios, mas sim a sua associação com o tráfico e o comércio ilícito de drogas.

Palavras-chave Análise por conglomerados, homicídio.

1 Universidade de Pernambuco (UPE), Faculdade de Ciências Médicas, Divisão de Cursos da Coordenação de Pós-Graduação, Recife (PE), Brasil. Correspondência e pedidos de separatas devem ser encaminhados a Maria Luiza C. de Lima no seguinte endereço: Núcleo de Pós-Graduação, Divisão de Cursos, Faculdade de Ciências Médicas, Universidade de Pernambuco, Rua Arnóbio Marques 310, Santo Amaro, CEP 50100-130, Recife, PE, Brasil. e-mail: luiza@cpqam.fiocruz.br
2 Fundação Oswaldo Cruz (FIOCRUZ), Centro de Pesquisas Aggeu Magalhães, Núcleo de Estudos em Saúde Coletiva, Rio de Janeiro (RJ), Brasil.

3 Universidade Federal de Pernambuco (UFPe), Hospital das Clínicas Bloco A, Programa de PósGraduação em Medicina Tropical.

4 FIOCRUZ, Centro Latino-Americano de Estudos sobre Violência e Saúde (CLAVES).

5 UPE, Faculdade de Ciências Médicas, Departamento de Medicina Social.
A questão da violência no Estado de Pernambuco vem assumindo, gradativa e insidiosamente, um papel central no cotidiano dos indivíduos, sendo o homicídio a mais cruel forma de expressão dessa violência. A análise da magnitude da violência, tendo 
como referência a taxa de mortalidade por homicídio em todas as faixas etárias para os estados do Brasil, revela que Pernambuco apresenta a mais alta taxa de homicídios para o ano de 1998, 58,8 por 100000 habitantes, bem acima da média do país, de 25,9 por 100000 habitantes (1). Em 2001, a taxa de homicídios no Estado de Pernambuco se mantinha em 58,8 por 100000 habitantes, ainda bem acima da média do país, de 27,8 por 100000 (2). Um estudo realizado por nosso grupo, com foco na faixa mais atingida, ou seja, homens de 15 a 49 anos, revelou, para o período de 1980 a 1998, um incremento nas taxas de homicídios da ordem de 246,8\% para o Estado. Para a capital, Recife, esse crescimento foi de $389,8 \%$; para a Região Metropolitana da capital, de $273,3 \%$; e para o interior, de $165,0 \%$ (3).

Vários estudos ecológicos em estados do Brasil têm apontado a relação entre os homicídios e as condições de vida (4-7). Outros, além de buscar possíveis associações entre as desigualdades sociais e a situação de violência, têm, a partir das técnicas de análise exploratória espacial, mapeado as áreas e as populações de risco (8-12). Contudo, a maioria desses estudos tem sido realizada em capitais, onde é possível localizar conglomerados de pobreza. Quanto à determinação, os estudos abordam a violência estrutural, que, segundo a classificação de Minayo e Souza (13), é configurada a partir das desigualdades sociais que crescem preponderantemente entre a população urbana. Mello Jorge (14), ao identificar os estados detentores dos maiores índices de violência contra jovens, ou aqueles com maior crescimento desses índices, verificou que o Rio de Janeiro, Pernambuco, o Acre, Mato Grosso do Sul e São Paulo correspondiam também aos estados em que se pode verificar a existência de redes e a maior inserção do narcotráfico.

Dessa forma, o presente estudo difere da maioria dos trabalhos já publicados acerca desse tema por várias razões: primeiro, na literatura brasileira há poucos estudos sobre violência com análise por conglomerados, e os existentes foram realizados em ca- pitais; segundo, o presente estudo incorpora novas técnicas de análise espacial para identificar áreas de conglomerados de homicídios; terceiro, o Estado de Pernambuco oferece um cenário particular para análise, não só pela magnitude das taxas de homicídios, mas também por conta da existência de importantes conflitos sociais resultantes do tráfico de drogas, principalmente na chamada área do Polígono da Maconha, situada no interior do Estado.

Assim, o objetivo deste estudo foi identificar conglomerados de violência em dois períodos (1980 a 1984 e 1995 a 1998) das últimas duas décadas do século XX, através da utilização do indicador local de autocorrelação espacial (LISA).

\section{MATERIAIS E MÉTODOS}

O Estado de Pernambuco está dividido em 10 regiões de desenvolvimento (RD) que representam subgerências administrativas: Região Metropolitana do Recife, Mata Norte, Mata Sul, Agreste Meridional, Agreste Central, Agreste Setentrional, Pajeú/ Moxotó, Itaparica, São Francisco e Araripe (15) (figura 1A). O presente estudo também considerou como dimensão geográfica, para análise dos dados, a chamada área do Polígono da Maconha, que abrange municípios do interior do Estado (figura 1B).

De 1980 a 1984, o Estado tinha 167 municípios. No ponto médio do período, a população masculina de 15 a 49 anos era de 1364377 habitantes, representando $21,6 \%$ da população total do Estado. No período de 1995 a 1998, com a criação de novos municípios, o Estado passou a totalizar 184 municípios. A população de homens na faixa dos 15 a 49 anos era, no ponto médio do período, de 1833280 habitantes, perfazendo $25,1 \%$ da população total.

As informações sobre homicídios foram obtidas junto ao Sistema de Informações sobre Mortalidade (SIM/ DATASUS). Os dados foram analisados com os programas Statistical Package for the Social Sciences (SPSS), Arcview e S-Plus. As taxas de mortalidade por homicídio foram calculadas por município e submetidas a uma análise univariada, através da construção de gráficos de caixa, histogramas e gráficos de normalidade (QQ plot). Para garantir maior estabilidade na análise dos dados por município, estudou-se a taxa média de mortalidade por homicídio agrupada para os períodos de 1980 a 1984 e 1995 a 1998. A construção dos coeficientes foi descrita anteriormente (3).

A base cartográfica do Estado de Pernambuco usada neste trabalho foi a referente ao ano de 1991, contendo 167 municípios digitalizados, cedida pelo Departamento de Cartografia da Universidade Federal de Pernambuco (UFPE). Assim, para utilizar a base cartográfica, foi necessário somar a população e o número de óbitos ocorridos nos municípios criados entre 1995 a 1998 aos dados dos municípios a partir dos quais esses novos municípios se originaram. A análise espacial foi conduzida utilizando-se a matriz de vizinhança como matriz de proximidade espacial baseada na existência de áreas adjacentes (16).

A fim de explorar a dependência espacial, os autores calcularam o coeficiente de Moran, o qual varia de -1 a +1 , sendo que os valores próximos dos extremos $(-1$ ou +1$)$ indicam uma maior autocorrelação (um coeficiente positivo indica um conglomerado de valores semelhantes, enquanto que um coeficiente negativo indica a adjacência de valores dessemelhantes) (16). Para localizar os conglomerados ou clusters de municípios com taxas de homicídio altas e baixas, foi utilizado o LISA. Por último, foi construído o mapa de Moran, que permite identificar os municípios com LISA estatisticamente significativo e, ao mesmo tempo, pode revelar se o agrupamento de municípios tem taxas de homicídio altas ou baixas (16-19).

\section{RESULTADOS}

A análise univariada revelou uma distribuição aproximadamente normal para as taxas de homicídios em homens de 15 a 49 anos, calculadas por 
FIGURA 1. Regióes de desenvolvimento e Polígono da Maconha, Estado de Pernambuco, Brasila

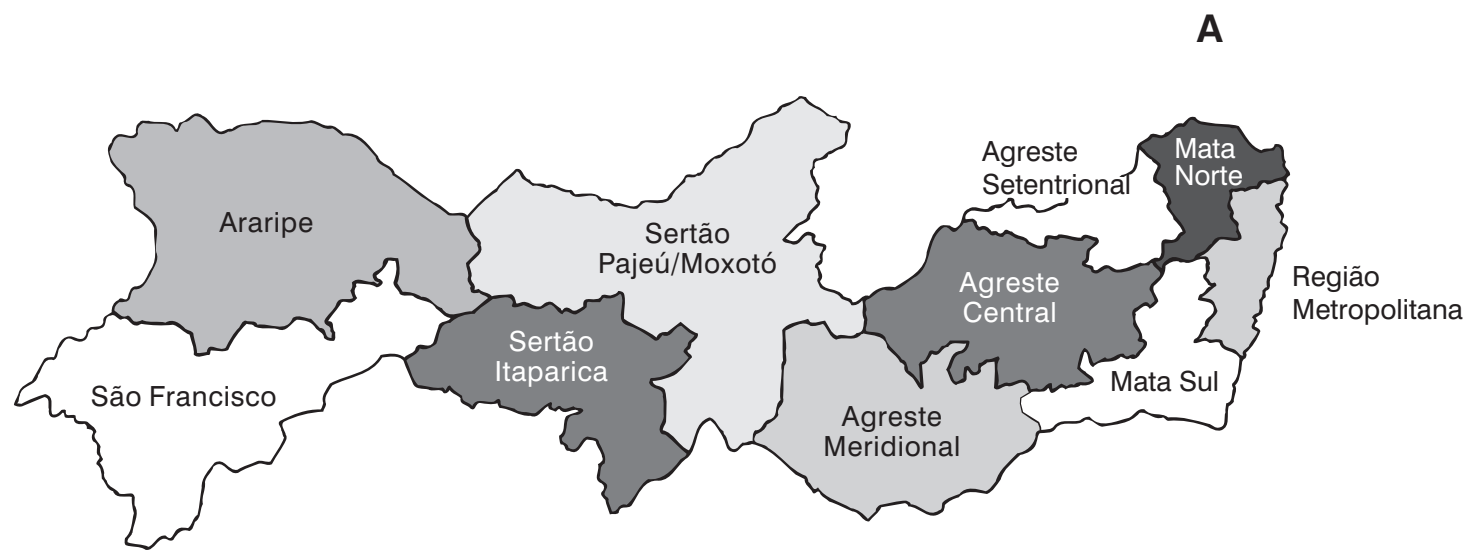<smiles>NC(F)(F)C(N)(N)S</smiles>

B

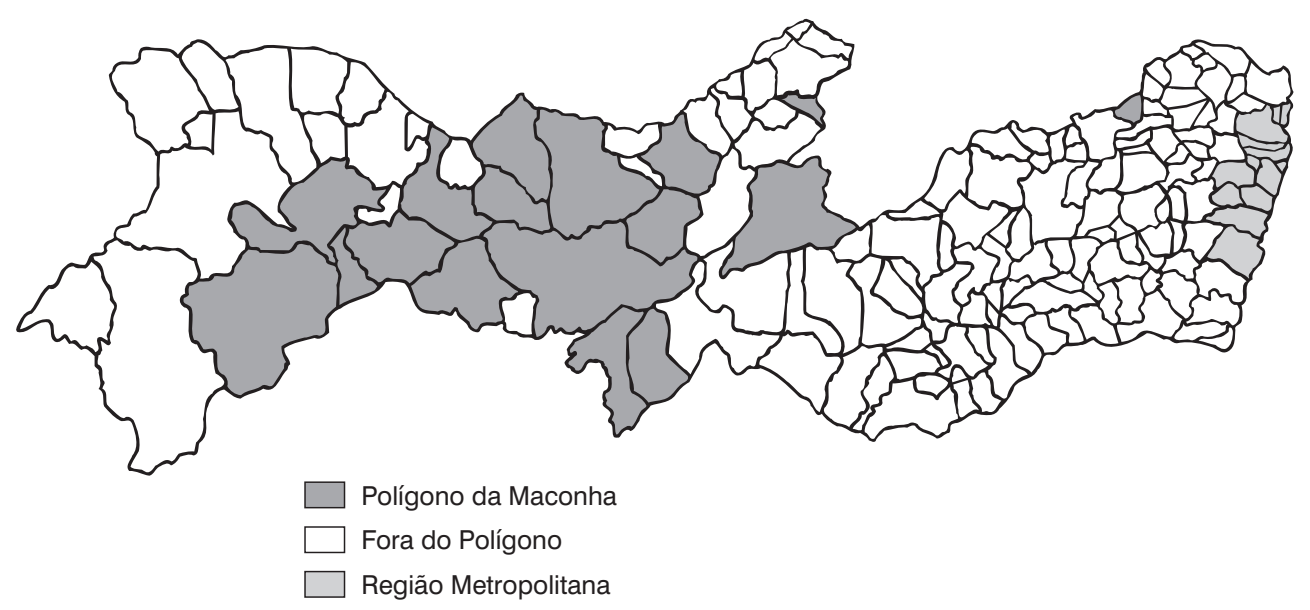

${ }^{a}$ A) Regióes de desenvolvimento; B) Polígono da Maconha. O mapa foi cedido pelo Departamento de Cartografia da Universidade Federal de Pernambuco (UFPE), e a divisão em municípios reflete o ano de 1991 (167 municípios). Escala aproximada 1:4 600000.

município, em ambos os períodos analisados, o que justifica a utilização de técnicas de análise espacial que pressupõem normalidade. O coeficiente de Moran para o período de 1980 a 1984 foi de 0,392 , e para o período de 1995 a 1998 , de 0,291 ( $P<0,001)$. O valor positivo do teste de Moran permite inferir que áreas vizinhas possuem taxas de homicídio semelhantes, indicando a existência de conglomerados. Assim, os municípios com coeficientes elevados de homicídios estão próximos a outros com o mesmo perfil, e aqueles com valores baixos situam-se nas vizinhanças de outros municípios com esta mesma característica.

Através do mapa de Moran, foi possível identificar os municípios para os quais os valores de LISA foram estatisticamente significativos $(P<0,05)$, além dos conglomerados com altas e baixas taxas de mortalidade por homicídio. A figura 2A mostra as áreas que apresentam dependência espacial com significância estatística para o período de 1980 a 1984 . Verifica-se um padrão espacial não-aleatório, com conglomerados de municípios que apresentam altas taxas de mortalidade por homicídio; isso se observa em 11 municípios de um total de 24 na RD Mata Sul, em dois municípios de um total de 14 na 
FIGURA 2. Conglomerados de municípios com indicador local de autocorrelação espacial (LISA) significativo, Estado de Pernambuco, Brasila

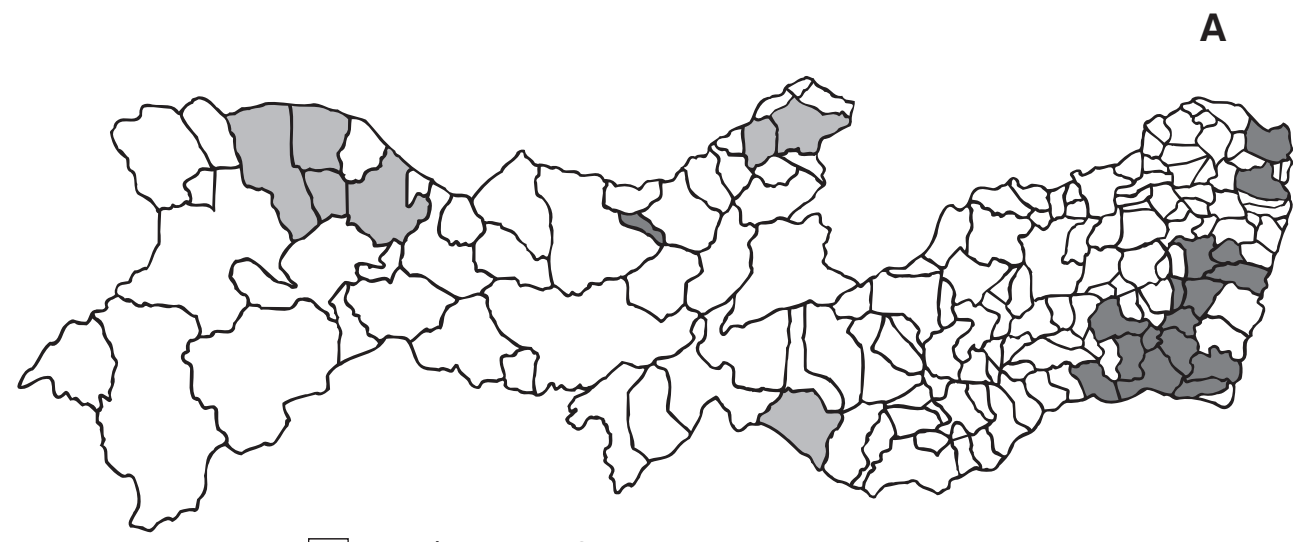

Municípios com LISA não significativos

Agrupamento de municípios com LISA significativos (Alto-Alto)

Agrupamento de municípios com LISA significativos (Baixo-Baixo)<smiles>NC(F)(F)C(N)(N)S</smiles>

B

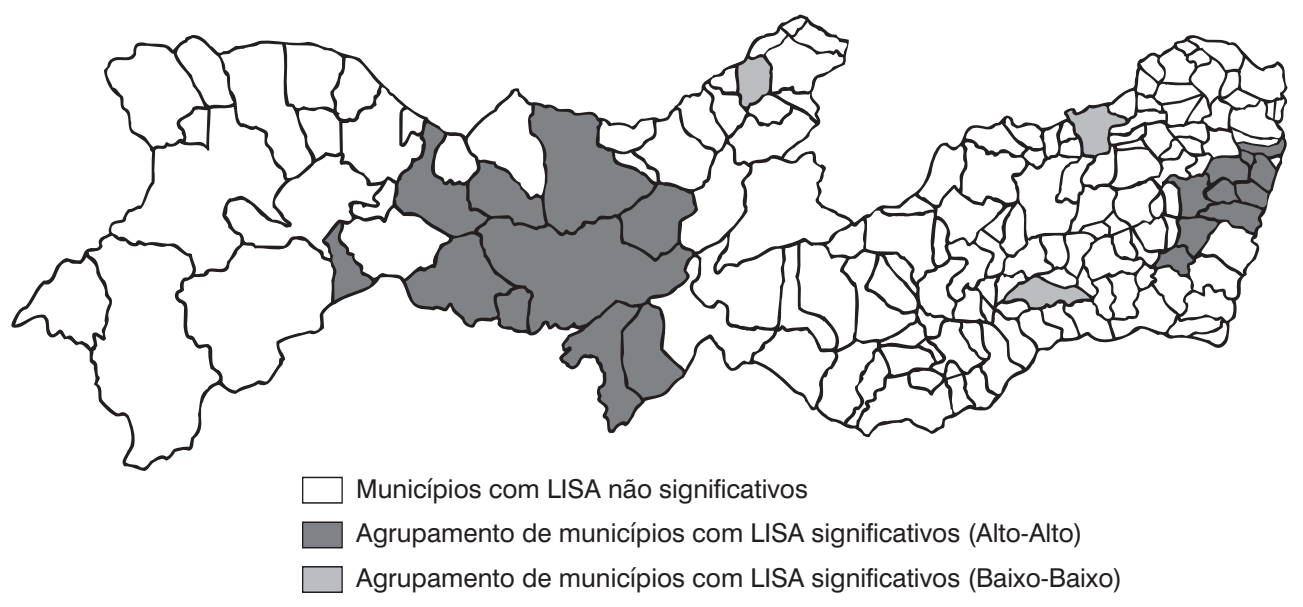

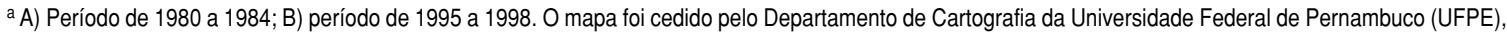
e a divisão em municípios reflete o ano de 1991 (167 municípios). Escala aproximada 1:4 600000.

RD Metropolitana, e em um município de um total de 26 na RD do Pajeú/ Moxotó. A figura 2B, referente ao período de 1995 a 1998, revela dois pólos com LISA significativo de alto valor. No primeiro pólo, verifica-se um processo de transição da violência, que predominava na RD da Mata Sul e passa a predominar na RD Metropolitana; nesse período, aparecem apenas três municípios na RD Mata Sul, de um total de 24, e oito na RD Metropolitana, de um total de 14 . No outro pólo está caracterizado o processo de interiorização, com nove municípios situados nas RDs de Itaparica e São Francisco e uma extensa área na RD do Pajeú/Moxotó, áreas estas localizadas na região denominada Polígono da Maconha, que abrange 21 municípios.

\section{DISCUSSÃO}

A análise do padrão espacial de mortalidade por homicídios no Estado de Pernambuco revelou conglomerados de municípios com áreas distintas nos dois períodos estudados. No primeiro período (1980 a 1984), identificou-se um conglomerado de violência na RD da Mata Sul, que foi se deslocando 
ao longo dos anos. De 1995 a 1998, verifica-se a formação de dois pólos de homicídios no Estado de Pernambuco: o primeiro que se deslocou da Mata Sul para a Região Metropolitana do Recife, e o segundo no interior do Estado, situado no Polígono da Maconha.

Minayo e Souza, ao classificarem a violência estrutural que ocorre nos países em desenvolvimento, apontam como causa os níveis excessivos de pobreza relativa e desigualdade social (13). O indicador de condições de vida (ICV) (19) para o ano de 1980 para as regiões da Mata Norte, Mata Sul e Região Metropolitana apresentou valores medianos de 0,418, 0,415 e 0,512, respectivamente, o que indica condições de vida semelhantes. Em 1991, a RD da Mata Sul apresentou um ICV de 0,470, a RD Metropolitana de 0,613, a RD do Sertão Pajeú/Moxotó de 0,502, do Sertão Itaparica de 0,522, do Sertão do São Francisco de 0,515, e do Sertão do Araripe de 0,463 (19), valores também semelhantes entre si.

Nas regiões em que predominaram os conglomerados, além do ICV, foram analisados outros processos sociais que fazem parte da teia de causalidade da violência. A Mata Sul foi uma dessas regiões, pois apresentou o maior número de municípios violentos no primeiro período: 11 dos 16 municípios que compunham os conglomerados se localizavam nessa região. Por isso foram investigados outros processos que pudessem explicar a diferenciação na mortalidade por homicídios na RD da Mata Sul em relação à Mata Norte.

Tanto na RD da Mata Norte quanto na da Mata Sul, a atividade econômica predominante é a monocultura da cana de açúcar. Contudo, alguns aspectos culturais e sociais diferenciam essas duas regiões. Estudos sobre a mesorregião da Mata Pernambucana indicam que este espaço passa por uma grave crise econômica e social, cuja raiz estrutural está exatamente na elevada concentração da base produtiva na atividade sucroalcooleira, com baixos índices de produtividade da cana-de-açúcar, perpetuando um quadro de estagnação e ineficiência econômica, instabilidade e dependência ex- terna, subemprego e altos índices de desemprego sazonal (20). Na Mata Sul, a área explorada com a agricultura canavieira é mais extensa, e as repercussões da estagnação dessa atividade parecem mais intensas. Quanto aos valores culturais, observa-se que ainda persiste, nessa região, desde o tempo colonial, um padrão hierárquico, com predominância do poder senhorial, marcado pelo favoritismo, quando não pela violência física (21).

Conforme depoimento dos delegados regionais dessa mesorregião, a violência na Mata Norte difere daquela praticada na Mata Sul pela ocorrência intensa, nesta última, da pistolagem (crimes por encomenda praticados por pistoleiros, assassinos de aluguel, autores materiais dos crimes de encomenda), originada em um período em que era absoluta a impunidade dos crimes praticados contra os trabalhadores rurais por proprietários de terra (21). Atualmente, o próprio desemprego tem contribuído para a redução desse tipo de ocorrência. Todavia, o machismo e a impunidade, aliados à ausência de condições de trabalho e de uma vida digna, propiciam este cenário de desrespeito aos direitos humanos e de agressões sem limites. A essas condições específicas somam-se os problemas comuns à estrutura do meio rural: conflitos pela posse da terra, rixas entre vizinhos e, ainda, problemas semelhantes aos do meio urbano, como o alcoolismo e o uso de drogas (21).

No período de 1995 a 1998, o mapa se modifica, mostrando dois pólos nítidos: um na Região Metropolitana e outro no interior do Estado, no Polígono da Maconha (no primeiro pólo, aparecem três municípios da Mata Sul e oito municípios da Região Metropolitana; no segundo, aparecem 10 municípios, sendo nove localizados no Polígono da Maconha). O deslocamento espacial da violência da RD da Mata Sul para a Região Metropolitana parece ser, em parte, decorrente da proximidade com a Região Metropolitana, que se constitui em um pólo de atração devido às melhores condições socioeconômicas dessa região.

É na Região Metropolitana do Recife que se situam os quatro municípios mais populosos do Estado-Recife, Jaboatão dos Guararapes, Olinda e Paulista. Juntos, esses municípios abarcam 79,63\% da população da Região Metropolitana e 33,23\% da população de Pernambuco. O ritmo de crescimento populacional entre 1991 e 1996 foi de $1,14 \%$, superando o do interior, em torno de $0,49 \%$. A população está concentrada predominantemente nas áreas urbanas, que abrigam 94,76\% dos habitantes da região (22).

Um outro dado importante diz respeito à situação educacional na Região Metropolitana do Recife, que, apesar de mostrar uma clara tendência de declínio nas taxas de analfabetismo e aumento nas de escolarização, no conjunto da população ainda apresenta altos percentuais de analfabetismo na população adulta e baixos índices de escolaridade na população de 10 anos ou mais (22). Esses insatisfatórios níveis de escolaridade têm reflexos negativos na inserção da população em idade ativa no mercado de trabalho; de forma geral, esses indivíduos ocupam postos de baixa qualificação e, conseqüentemente, baixa remuneração, constituindo um alvo preferencial para ingressar no mundo das drogas. É também na Região Metropolitana que ocorrem com maior intensidade as desigualdades sociais e, devido à maior densidade demográfica, os conflitos interpessoais e a formação de galeras, ou grupos de jovens que se reúnem com o objetivo de praticar atos lícitos (esportes, artes ou outra atividade social ou religiosa) ou ilícitos (roubos, furtos, consumo de drogas e outras infrações ou crimes). Às vezes esses grupos competem com outros de áreas diferentes, como uma forma de resguardar sua atuação em um determinado território. Esses são processos sociais que a literatura tem destacado como estando associados com as crescentes taxas de homicídio nos últimos 20 anos $(4-7,11)$.

O sertão do São Francisco, constituído pelas RDs de São Francisco e Itaparica, apresenta especificidades na ocupação social do espaço que vão configurar realidades sociais distintas. $\mathrm{O}$ expressivo dinamismo econômico ocorrido na região do São Francisco re- 
presentou um aprofundamento das desigualdades sociais intra-regionais preexistentes nesse espaço. Essas desigualdades foram se acentuando a partir da década de 1970, quando houve um investimento com alocação de recursos públicos em torno da microrregião de Petrolina, com o desenvolvimento da agricultura irrigada destinada à exportação. Esse lado dinâmico da microrregião atraiu habitantes de várias outras localidades, que se estabeleceram principalmente em Petrolina, concorrendo para a criação de bolsões de pobreza.

Diferentemente, na RD de Itaparica, o grande deslocamento populacional resultante da formação do lago de Itaparica, em 1989, gerou mudanças cujo impacto ainda se faz sentir, notadamente no que se refere às populações reassentadas. Nas áreas destinadas aos projetos de reassentamento e irrigação, a falta de infra-estrutura e de preparo das pessoas, capacitando-as para assumir um novo modo de vida, gerou ociosidade, consumo de bebidas e drogas e violência. A partir daí, surgiu o cultivo da maconha como alternativa de sobrevivência para os pequenos agricultores da região, com base na ação de grupos criminosos organizados, que pagam pela erva 10 vezes mais do que os agricultores recebiam pelos cultivos tradicionais $(15,23,24)$.

O relatório de maio de 1997 da comissão externa da câmara dos deputa- dos sobre a violência no Polígono da Maconha em Pernambuco reconhece a área (limitada pelas margens do São Francisco e pelas cidades de Petrolândia, Salgueiro, Ouricuri e Petrolina) como pólo produtor de substâncias entorpecentes, com destaque para o plantio da maconha. $\mathrm{O}$ documento relata que organizações criminosas locais, denominadas "comandos caipiras", têm interligação com indivíduos do crime organizado do Rio de Janeiro, e que suas ações são respaldadas pela venda clandestina de munições ilegais, pela receptação do fruto de roubos de comerciantes locais e pela proteção de famílias influentes nas regiões onde atuam. As atividades do narcotráfico na região, acrescenta o relatório, empregam mão-de-obra local no plantio, além de pistoleiros nas ações criminosas. Este cenário é ainda secundado por disputas entre famílias da região por terra, poder político e, em certa escala, pelo controle do tráfico de drogas e armas pesadas. A repressão policial ao plantio muitas vezes ocasiona um recrudescimento da violência, fazendo com que os grupos passem a realizar assaltos nas rodovias que cortam as localidades (25).

Beato Filho et al. (26), em estudo realizado em Belo Horizonte, Estado de Minas Gerais, com foco na análise espacial dos homicídios, revelaram que não são as condições socioeconômicas em si as responsáveis pelos conglome- rados de homicídios, mas o fato de áreas com condições socioeconômicas precárias (como favelas) serem também assoladas pelo tráfico e comércio ilícito de drogas (26). Zaluar et al. (27) chamam a atenção para o papel do crime organizado, bem como do tráfico de drogas e de armas, como fatores predominantes na estruturação da criminalidade metropolitana, particularmente quando associados a uma política exclusivamente repressiva de combate às drogas e a escolhas políticas e institucionais inadequadas para o enfrentamento da pobreza urbana (27).

Apesar da simplificação diante de tantos processos sociais imbricados na determinação da violência, os resultados desta pesquisa encontram respaldo em uma literatura que enfatiza o incremento dos homicídios como associado a uma criminalidade cada vez mais decorrente do tráfico de drogas. Isso de forma alguma significa que apenas esse tipo de causalidade ocorre nas regiões estudadas, mas indica que o incremento resultante da violência associada ao narcotráfico contribui para a formação de conglomerados de violência.

Agradecimentos. Projeto financiado pela Fundação de Amparo à Ciência e Tecnologia do Estado de Pernambuco (FACEPE), processo $n^{\circ} 23-C D-08 / 00-$ 01/01-26.

\section{REFERÊNCIAS}

1. Waiselfisz JJ. Mapa da violência II: os jovens do Brasil. Brasília: UNESCO; 2000.

2. Brasil, Ministério da Saúde. DATASUS [site da Internet]. Disponível em: http://tabnet. datasus.gov.br/cgi/sim/obtmap.htm. Acessado em abril de 2005.

3. Lima MLC, Souza ER, Ximenes RAA, Albuquerque MFPM, Bitoun J, Barros MDA. Evolução de homicídios em Pernambuco: análise por área geográfica, de 1980 a 1998. Rev Saude Publica. 2002;36(4):462-9.

4. Barata RB, Ribeiro MCSA, Guedes MBLS, Moraes JC. Intra-urban differentials in death rates from homicide in the city of São Paulo, Brazil, 1988-1994. Soc Sci Med. 1998;47(1): 19-23.
5. Macedo AC, Paim JS, Silva LMV, Costa MCN. Violência e desigualdade social: mortalidade por homicídios e condições de vida em Salvador, Brasil. Rev Saude Publica. 2001;35(6): $515-22$.

6. Souza ER, Assis SG, Silva CMFP. Violência no município do Rio de Janeiro: áreas de risco e tendências da mortalidade entre adolescentes de 10 a 19 anos. Rev Panam Salud Publica. 1997;1(5):389-98.

7. Szwarcwald CL, Bastos FI, Viacava F, Andrade CLTA. Income inequality and homicide rates in Rio de Janeiro, Brazil. Am J Public Health. 1999;89(6):845-50.

8. Cruz OG. Homicídios no Estado do Rio de Janeiro: análise da distribuição espacial e sua evolução [dissertação de mestrado]. São Paulo: Universidade de São Paulo; 1996.

9. Lima MLC, Ximenes R. Violência e morte: diferenciais da mortalidade por causas externas no espaço urbano do Recife, 1991. Cad Saude Publica. 1998;14(4):829-40.

10. Najar AL. Desigualdades sociais e análise espacial: uma aplicação para o município do Rio de Janeiro utilizando sistemas de informações geográficas [tese de doutorado]. Rio de Janeiro: Instituto Universitário de Pesquisas do Rio de Janeiro; 1997.

11. Paim JS, Costa MCN, Mascarenhas JCS, Silva LMV. Distribuição espacial de violência por causas externas em Salvador, Bahia, Brasil. Rev Panam Salud Publica. 1999;6(5):321-32. 
12. Santos MS. Homicídios em Porto Alegre, 1996: análise ecológica de sua distribuição e contexto sócio-espacial [dissertação de mestradol. Rio de Janeiro: Escola Nacional de Saúde Pública, Fundação Oswaldo Cruz; 1999.

13. Minayo MCS. Inequality, violence and ecology in Brazil. Cad Saude Publica. 1994;10(2): 241-50.

14. Mello Jorge MH. Como morrem nossos jovens? Em: Comissão Nacional de População e Desenvolvimento. Jovens acontecendo nas trilhas das políticas públicas. Brasília: CNPD; 1998. Pp. 209-92.

15. Secretaria de Planejamento e Desenvolvimento Social do Estado de Pernambuco. Mesorregião do São Francisco pernambucano: microrregiões de Petrolina e Itaparica. Recife: SEPLANDES, Instituto de Planejamento de Pernambuco (CONDEPE); 1998.

16. Carvalho MS, Câmara G, Cruz OG, Correa V. Análise espacial de áreas. Em: Druck $\mathrm{S}$, Carvalho MS, Câmara G, Monteiro AMV, eds. Análise espacial de dados geográficos. Disponível em: http:/ /www.dpi.inpe.br/gilberto/ livro/analise/. Acessado em abril de 2005.

17. Anselin L. Local indicators of spatial association-LISA. Geogr Anal. 1995;27(2):93-115.

18. Ord JK, Getis A. Local spatial autocorrelation statistics: distributional issues and an application. Geogr Anal. 1995;27(4):286-305.
19. Programa das Nações Unidas para o Desenvolvimento, Instituto Brasileiro de Geografia e Estatística, Instituto de Pesquisa Econômica Aplicada, Fundação João Pinheiro. Atlas de desenvolvimento humano [CD-ROM]. Em: PNUD, IBGE, IPEA, Fundação João Pinheiro. Desenvolvimento humano e condições de vida: indicadores brasileiros. Brasília: PNUD, IBGE, IPEA, Fundação João Pinheiro; 1998.

20. Secretaria de Planejamento e Desenvolvimento Social do Estado de Pernambuco. Mesorregião da mata pernambucana: microrregiões da Mata Setentrional, da Mata Meridional e de Vitória de Santo Antão. Recife: SEPLANDES, Instituto de Planejamento de Pernambuco (CONDEPE); 2000.

21. Secretaria de Planejamento e Desenvolvimento Social do Estado de Pernambuco. Plano de desenvolvimento sustentável da Mata Pernambucana. Recife: SEPLANDES, Instituto de Planejamento de Pernambuco (CONDEPE); 1998.

22. Secretaria de Planejamento e Desenvolvimento Social do Estado de Pernambuco. Plano de ação regional 2000-2003: orçamento participativo estadual. Região de desenvolvimento Mata Norte, Mata Sul, Metropolitana do Recife, Pajeú-Moxotó, Itaparica e São Francisco. Recife: SEPLANDES, Instituto de Planejamento de Pernambuco (CONDEPE); 1999.
23. Secretaria de Planejamento e Desenvolvimento Social do Estado de Pernambuco. Plano de desenvolvimento do sertão de Pernambuco. Recife: SEPLANDES, Instituto de Planejamento de Pernambuco (CONDEPE); 1997.

24. Fraga PCP. Juventude, narcotráfico e violência no Brasil: para além do rural e do urbano. Em: Ribeiro AMM, Iulianelli JAS, orgs. Narcotráfico e violência no campo. Rio de Janeiro: DP\&A; 2000. Pp. 81-106.

25. Brasil, Câmara dos Deputados. Violência no polígono da maconha. Brasília: Comissão Externa; 1997. (Relatório do deputado Fernando Ferro).

26. Beato Filho CC, Assunção RM, Silva BFA, Marinho FC, Reis IA, Almeida MCM. Conglomerados de homicídios e o tráfico de drogas em Belo Horizonte, Minas Gerais, Brasil, de 1995 a 1999. Cad Saude Publica. 2001;17(5): 1163-71.

27. Zaluar A, Noronha JC, Albuquerque C. Violência: pobreza ou fraqueza institucional? Cad Saude Publica. 1994;10(supl 1):213-7.

Manuscrito recebido em 11 de novembro de 2004. Aceito em versão revisada em 1 de março de 2005.

ABSTRACT Objectives. To analyze the spatial distribution of homicide mortality rates among males 15 to 49 years old in the state of Pernambuco, Brazil, for the periods of 1980 to 1984 and 1995 to 1998, and to identify violence clusters.

Violence clusters in Pernambuco, Brazil tality Information System. The mean homicide mortality rate was estimated for each municipality in the state for the two periods. The Moran coefficient was calculated to determine spatial autocorrelation. (The Moran coefficient ranges from -1 to +1 , with a positive coefficient indicating a cluster of similar values, and a negative coefficient indicating adjacent dissimilar values.) To identify clusters of municipalities with either high or low homicide mortality rates, the local indicator of spatial association (LISA) was used. Finally, a Moran map was constructed to identify municipalities with statistically significant LISA values and to identify clusters of municipalities with either high or low homicide mortality rates.

Results. The Moran coefficient for 1980-1984 was 0.392, and for 1995-1998 it was 0.291 ( $P<0.001$ ). In the $1980-1984$ period, one cluster of high homicide mortality rates was found in the Mata Sul region of the state, close to the metropolitan region of the state capital, Recife. In the 1995-1998 period, two violence clusters were identified: a predominantly urban one in the Recife metropolitan region, and the other in the state interior, in an area known as the "Marijuana Polygon" (Polígono da Maconha).

Conclusion. This study suggests that the violence clusters are not the result of the socioeconomic conditions per se, but rather the consequence of the interaction between poor economic conditions and drug trafficking.

Keywords Cluster analysis, homicide. 